The strengths of the book are in its easily readable style and in the way in which laboratory techniques and methods, and the limitations of these, are appropriately interspersed with the clinical problems they have been designed to help solve. There is emphasis on the need for proper and relevant requests, the importance of proper specimens, the proper use of serological tests and a more rational approach to antibiotic use all bear the stamp of an author experienced in the problems at first hand. The concept of the microbiological ward round starting daily in the pharmacy is one which many consultant microbiologists could well emulate provided of course that this does not lead to the neglect of daily laboratory supervision of which we are warned in Chapter 3.

It is inevitable that this very personal and enthusiastic book which is really the first of its kind should, in achieving a readable style, sacrifice some literary and microbiological precision which longer and more comprehensive books might achieve.

Many might enjoy the apparently random selection from the Oxford Dictionary of Quotations which introduces not only every chapter, but certain parts within a chapter; if these quotations have somehow helped Dr Grüneberg to maintain his momentum then they may be forgiven. Others may be irritated by an exanthem of brackets which appears to pervade the earlier rather tr.an the later chapters; again, these serve to give a technical definition to non-technical descriptions and as such may be almost unavoidable. There are some anomalies which creep in when general principles are illustrated by specific examples in brackets: it was probably never the author's intention to suggest that the use of tetanus antitoxin should await the isolation of the organism nor is it strictly accurate to suggest that antibiotic-associated colitis is an example of resistant organisms invading tissues after the use of broad spectrum antibiotics. It is to be hoped that the emphatic statement that any child 'under the age of five years brought to see a general practitioner should have a urine sample cultured' will be regarded as illustrative rather than mandatory.

Nonetheless this is an important and enjoyable book written by an enthusiast whose optimism allows him to think in terms of a world-wide antibiotic policy in the future: it can be thoroughly recommended for medical libraries, and should be obligatory reading for junior hospital doctors and indeed all those who use clinical microbiological services.

M.W.N. NichOLLS

Royal West Sussex Hospital, Chichester, W. Sussex

\section{Occupational Hygiene. An Introductory Guide}

By A. L. Jones, D. M. W. Hutcheson and S. M. Dymott. Pp. 182, illustrated. Croom Helm, London, 1981. £9.95.

I recently reviewed for this Journal the new edition of Schilling's Occupational Health Practice. At that time I said that some of the chapters filled the gaps in medical training of the extra disciplines required for the practice of occupational medicine. One such gap was occupational hygiene. This new introductory guide to occupational hygiene provides a further summary of this topic.

A full understanding of occupational hygiene is as essential to the occupational physician as a knowledge of epidemiology and statistics is to the present day medical graduate. The hygienist is one of the health team in industry reducing by his work opinions to facts. Doctors must also recognize that the occupational health nurse is also a member of that team and today is sometimes not only better trained than the physician to carry out some of the environmental measures but also has more time than the part-time occupational physician to devote to such tasks. One of the co-authors o⿸丆⿰丨丶⿵ this book is a senior occupational health nurse thus under lining the role of the nurse in this field.

The opening chapters provide simple basic physiologica and chemical principles. The book then goes on to describe? the techniques of measurement including the planning oD surveys and, very briefly, biological monitoring-stilf essential to measure the success or failure of environmenta $\bar{E}$. control measures in the workplace. There are useful lists of industrial hygiene consultants, suppliers of sampling equip@ ment and a glossary of terms and abbreviations. Eacln chapter has an adequate bibliography of suggested further? reading.

It is a clear, concise and well written introduction tooccupational hygiene, although expensive even by today' prices.

The authors recommend the book as both a learning and reference text for safety officers, safety representatives ans occupational health nurses. I would suggest that occupationaf. physicians, especially those working part-time, could alsofr usefully study this book if only to equip themselves to deaf with the questions posed to them by the authors' suggested readers armed with the knowledge derived from this book.

J.C. Graham $\vec{N}$ Chief Medical OfficeథO

H. J. Heinz Company Limited London.

\section{Rehabilitation of the Hand}

By C. B. Wynn Parry. 4th edn. Pp. xv+409, illustrate Butterworths, London, 1981. $£ 30.00$.

Each of the previous editions of this unique book has beet an improvement on the last and this is no exception. The title has always suggested a volume of more specialized and limited appeal than does a thorough reading of the text which has always covered far more than matters relating to the hand alone-anatomically up as far as the cervical nerve roots and in the best traditions of rehabilitation out into the community and the workplace where the success of the measures applied meet the sternest test.

The fourth edition has been considerably rewritten withou? becoming intolerably weighty in the process. There is. some excellent new material on pain mechanisms, measure ment and on pain treatment. Particularly since sceptics have had their suspicions about visual analogue scales confirment. by the observations of Bird and Wright that anyone pre sented with such a scale tends to mark it at a point corres. ponding to the golden section, one would tend to disseng from the view that 'it is now accepted that the use of a visua analogue scale is a valid and reproducible means of assessing pain'. But in this book other validated means are explaineक in detail. There is much in this section of interest to those whos might profess no interest in rehabilitation. Likewise the clarity and detailed exposition of the proper use of electro. diagnostic methods makes the book essential reading fof anyone in neurology, orthopaedics or rheumatology who asks for or performs electromyography or nerve conduction tests.

There are many texts in which long accepted positions on difficult topics are merely reiterated. One of the great virtues of the author's experience and perceptive approach is that such views are challenged and where necessary firml $\bar{\varnothing}$ rejected, as for instance in the case of Sudeck's atrophy being related to the type of personality. I am delighted to see that Wynn Parry dismisses this ill founded view which prejudices the management of patients from the outset. His review o? 